\title{
What Do Teachers Need to Support English Learners?
}

\author{
Marjorie N. Gomez ${ }^{1} \&$ Nagnon Diarrassouba ${ }^{1}$ \\ ${ }^{1}$ Department of Leadership and Learning, College of Education, Grand Valley State University, USA \\ Correspondence: Nagnon Diarrassouba, Department of Leadership and Learning, College of Education, Grand \\ Valley State University, 401 Fulton Street West, Grand Rapids, MI 49504, USA. Tel: 616-331-6611. E-mail: \\ diarrasn@gvsu.edu
}

\author{
Received: February 9, 2014 Accepted: March 14, 2014 Online Published: April 14, 2014 \\ doi:10.5539/elt.v7n5p89 URL: http://dx.doi.org/10.5539/elt.v7n5p89
}

\begin{abstract}
This study explored K-8 teachers' perceptions of their preparation and the challenges they encountered in delivering instruction to culturally and linguistically diverse learners. Using a mixed method research design, data were collected through a web-based survey from teachers in the state of Michigan. Researchers used chi-square tests to investigate the relationship between teachers' preparation and their knowledge of their diverse learners' learning needs. Qualitative comments were examined, organized, and summarized to illustrate key themes in each question under study. Findings revealed that teachers' perceptions of their preparation to teach linguistically and culturally diverse students were correlated with cultural diversity or lack of cultural diversity in their classrooms. Whereas teachers stated they felt prepared to teach heterogeneous classes, they encountered challenges in delivering instruction to English learners. In addition, teachers stated that cultural awareness training did not adequately prepare them to integrate cultural elements in their daily instructional practices.
\end{abstract}

Keywords: English learners, multicultural education, teacher training

\section{Introduction}

Researchers in education and language teaching have shown that many educators are not adequately prepared to teach culturally and linguistically diverse students (Gay, 2002; Hutchinson \& Hadjioannou, 2011; Verdugo \& Flores, 2007; Echevarria, Vogt, \& Short, 2007). Empirical studies have indicated that English language learners (ELLs) continue to academically lag behind their native English-speaking peers. One reason often put forth by researchers to explain ELLs' academic underachievement relates to content-area teachers' inadequate preparation to teach culturally and linguistically diverse learners (Santoro, 2007).

Classroom teachers' attitudes, behaviors, and perceptions have been shown to have a significant influence on students' attitudes toward learning and academic performance (Banks, 2005). Also, researchers have demonstrated that being sensitive to and comprehending various cultures enables teachers to be effective (Gay, 2002; Johnson, 2003). It has become a necessity for K-12 teachers in the United States to be adequately prepared regarding cultures as the number of ELLs has significantly increased. In 2011, a comparative study conducted by the National Clearinghouse for English Language Acquisition (NCELA) showed that the number of ELLs registered in U.S. schools from pre-kindergarten through 12th grade increased by 51\% between 1999 and 2009 (National Clearinghouse for English Language Acquisition, 2011).

Estimates of teachers who have participated in professional development related to teaching in heterogeneous classes are difficult obtain. In a national survey, the NCELA (2008) revealed that less than one sixth of colleges offering pre-service teacher preparation included training for working with ELLs. In that survey, $80 \%$ of the teachers stated that they had participated in professional development related to their state or district curriculum, but only $26 \%$ had received professional development workshops that focused on working with ELLs. Furthermore, approximately $57 \%$ of the teachers reported that they needed more training to provide effective instruction for ELLs. So it is crucially important to continue investigations into teachers' perceptions of their preparation and the challenges they encounter in teaching culturally and linguistically different learners.

\section{Theoretical Framework and Literature Review}

Multicultural education has become, over the years, the most popular term used to describe educational programs that integrate different ethnic, linguistic, and cultural aspects in curricula and instructional practices. Multicultural education is a theory and a philosophy whose advocates uphold the ideals of freedom, justice, and 
equality to help develop the intellectual competencies of children from various social-cultural groups who have been historically marginalized (Sleeter, 2008; Nieto, 2002).

The works of Banks (2005), Gay $(2000,2002,2010)$, and Nieto $(2000,2002)$ on multiculturalism have been widely used by educational organizations to develop programs, courses, and projects in multicultural education. They have been fervent advocates of an education that incorporates the ideals of democracy, social justice, pluralism, and equality. J. Banks and C. Banks (1997) have argued that school reforms that incorporate ideologies of pluralism and equality have the potential to contribute to broader social reforms, empowering all individuals. Such reforms should be unbiased and reflect understanding and acceptance of all students, considered within parameters of critical pedagogy and based on high expectations for all learners (J. Banks \& C. Banks, 1997; Nieto, 2002).

Banks (2005), Gay (2000), and Nieto (2002) have argued that multicultural education plays an important role in preparing teachers to meet the challenges in diverse classrooms. Banks has focused on curricula, Gay has focused on pedagogy, and Nieto has focused on education for social justice. Over time, Gay (2010) and Nieto $(2000,2002)$ have demonstrated that culturally relevant and responsive practices hold great potential for shaping academic outcomes for all students.

The preparation of teachers to work with ELLs has been well documented. However, most literature has focused on the preparation of language specialists such as English as a second language (ESL) or bilingual teachers (Lucas, Villegas, \& Freedson-Gonzalez, 2008; Arias, Garcia, Harris-Murria, \& Serna, 2010). Conversely, little research has been collected about the kind of preparation received by mainstream and disciplinary teachers who teach ELLs, and the knowledge they have regarding the educational needs of this diverse student group (Lucas et al., 2008).

\subsection{Culturally Responsive Teaching}

Research has conclusively shown that teachers who have developed multicultural competency are likely to be more successful at meeting heterogeneous learners' academic needs. Findings from empirical studies have been consistent regarding four major themes: (a) the development of culturally responsive teaching, (b) understanding of diverse learners' backgrounds, (c) adapting curricula to different cultures and backgrounds, and (d) holding high expectations for all learners (Gay, 2000; Arias et al., 2010; Darling-Hammond, 2006).

Gay (2000) has defined culturally responsive teaching as "the cultural knowledge, prior experiences, frames of reference, and performance styles of ethnically diverse students to make learning encounters more relevant to and effective for them" (p. 29). A culturally responsive teacher affirms students' identities by using their backgrounds as resources to teach and learn. Students have local funds of knowledge that can be utilized to validate their identities as knowledgeable individuals and as a foundation for future learning (Gonzalez \& Moll, 2002). Teachers who respect cultural differences are apt to believe that all students are capable learners, even when students enter school with ways of thinking, talking, and behaving that contrast with the dominant cultural model (Gay, 2002; Villegas \& Lucas, 2002). Moreover, culturally responsive teachers see themselves as responsible and capable intermediaries to bring about educational changes that will make schools responsive to all students.

Culturally responsive teaching moves beyond tolerance toward acceptance, which helps students incorporate their linguistic, cultural, and background resources into all aspects of schooling (Gay, 2002). Culturally responsive teaching is an important factor in all efforts that aim to improve the ability of future teachers to deal with the complex circumstances of contemporary schooling, which is increasingly influenced by ELLs (Karatzia-Stavlioti, Roussakis, \& Spinthourakis, 2009). Culturally responsive teaching requires that teachers change their methods to support the academic achievements of all students, especially ELLs, whose academic achievements and expectations are often lower than those of their English-speaking counterparts.

In a study about the development of culturally responsive teaching competencies and the implications for teacher education, Siwatu (2007) found that teachers who were culturally responsive were effective in their ability to connect with students from diverse cultural backgrounds. They helped students feel like important members of the classroom. In a similar vein, Siwatu's study_drawn from a population of 275 pre-service teachers enrolled in two teacher education programs in the Midwest-showed that there is a correlation between culturally responsive competence and culturally responsive outcomes. In other words, teachers who are successful in executing culturally responsive teaching practices tend to believe in the positive outcomes associated with culturally responsive pedagogy. 
Along the same lines, a study by Arias et al. (2010) related to competencies in secondary schools found that teachers needed to develop culturally responsive skills, such as incorporating students' background knowledge and community life, into their professional practices. They also found that teachers of ELLs needed to consider their students as resources that could be used to improve instruction and support learning in subject-matter classes. Studies by Arias et al. (2010) and Siwatu (2007) have demonstrated that teachers need to make their teaching methods culturally responsive.

\subsection{Utilizing Students' Backgrounds}

Many teachers lack an understanding of how diverse learners construct knowledge, how the lives of their students are connected to their success in school, and how to teach in a way that builds on what their students already know while extending learning beyond familiar elements (Gay, 2002; Villegas \& Lucas, 2002). Research has shown that teachers can deliberately access students' cultural backgrounds in daily learning practices (Gonzalez \& Moll, 2002).

Gutstein, Lipman, Hernandez, and Reyes' study (1997) provided evidence that utilizing students' backgrounds and experiential knowledge is essential in the learning-teaching process. The study's purpose was to examine how mathematics instruction was affected by the inclusion of students' culture and informal knowledge in the daily curriculum in an elementary/middle school attended mostly by Mexican American students. Using instructional practices that built upon the students' backgrounds, the teachers helped the students develop not only critical thinking, but also assisted in the development of critical reasoning about knowledge in general. Teachers in the study discovered a close relationship between teaching mathematics and producing leaders among students from marginalized groups. Using the students' backgrounds as a teaching tool was shown to be an effective strategy to help learners acquire academic knowledge.

The development of an effective learning environment requires the use of curricula and instructional practices that promote students' growth. Brown (2003) emphasized the importance of integrating learners' culture into curricula. His study described several instructional strategies used by 13 teachers from seven cities throughout the U.S. to create cooperative and academically productive classrooms. Of critical importance in this study was the finding that successful instructional strategies involved establishing an environment in which teachers addressed students' cultural, emotional, and cognitive needs.

\subsection{Importance of Expectations}

Another important element in delivering instruction to culturally and linguistically diverse learners is holding high expectations. Many instructional practitioners experience difficulties addressing the learning needs of ELLs (Santoro, 2007). A number of studies have supported the assertion that teachers who have high expectations for their students may positively affect students' academic achievement (Guillet, Martinek, Sarrazin, \& Trouilloud, 2002; Guskey, 2002).

For example, in an effort to identify the reasons Latino and African American students failed or succeeded in mathematics, Gutierrez (2000) conducted a mixed method case study in eight urban high school departments of mathematics. This study found that the success of African American and Latino students in mathematics was due to the fact that the schools and teachers had high expectations of their students. Teachers were accessible and focused on positive student strengths rather than their weaknesses. Gutierrez concluded that this positive culture in the mathematics department affected students' performance.

Similarly, an exploratory study of six secondary schools in California and Arizona about academic success was conducted to find the rationale for language-minority students' achievement. Donato, Henze, and Lucas (1990) found that one of the key features that promoted these students' academic achievement was holding high expectations for them.

\subsection{Teacher Preparation Needs}

As the U.S. ELL population increases, educators need to be well prepared to face cultural and linguistic diversity challenges and to comply with state and federal educational policies and standards (Bernhard, Diaz, \& Allgood, 2005). Also, teachers have to develop teaching strategies that utilize students' backgrounds (Echevarria et al., 2007). Aspects of diversity, such as culture and language, have to be integrated into instructional activities to enhance the learning experiences of both diverse students and their mainstream English-speaking peers (Woods, Jordan, Loudoun, Troth, \& Kerr, 2006).

Research has shown that many teachers have little knowledge about how to work effectively with culturally and linguistically different students. Teachers without proper training can experience feelings of anxiety, uncertainty, and intimidation (Guo, Arthur, \& Lund, 2009). Preparation and cultural responsiveness are critically important in 
the heterogeneous classroom setting (Bernhard et al., 2005). Teachers need guidelines to help them observe and interpret behaviors and beliefs to prevent negative assumptions associated with certain ethnic or linguistic groups. Yet few empirical studies have focused on examining teachers' perceptions of their preparation to teach in heterogeneous contexts.

\section{Purpose of Study}

The purpose of this study was to investigate K-8 teachers' knowledge and understanding of their students' learning needs, and their perceptions of how well prepared they are to effectively deliver instruction to diverse learners. To achieve this goal two major research questions were asked:

1) What are teachers' perceptions of their preparation to effectively deliver instruction to learners with diverse cultural and linguistic backgrounds?

2) What kind of knowledge and understanding do teachers have about their linguistically and culturally different students' learning needs?

It was hypothesized that most teachers in K-8 contexts were ill-prepared to teach in heterogeneous classrooms, which was reflected in the integration —or lack thereof —of their students' cultural backgrounds in instructional practices.

This study was based on a theoretical framework of multicultural education as conceived by Banks (2005), Gay (2000), and Nieto (2002). As noted previously, Banks has focused on curricula, Gay on pedagogy, and Nieto on social justice. Because of the dimensions that each of these experts represent, multicultural education was deemed suitable for this study.

\section{Method}

The research design was a single study using a mixed method approach in which qualitative and quantitative data were collected.

\subsection{Research Site}

The research site selected for this study was the Kent Intermediate School District (KISD) of Kent County, Michigan. KISD serves 20 local public school districts and all non-public schools within Kent County's boundaries. KISD, directly or indirectly, serves almost 400 schools, more than 130,000 students, and 7,000 educators. Also, it provides an array of services to educators and families (Kent Intermediate School District, 2011). One of the goals of KISD is to help schools understand, instruct, and support the academic growth of students from different cultural and linguistic backgrounds. In the case of ELLs, KISD provides a wide range of resources to more than 8,000 students. KISD claims to identify and promote effective practices for assessment, data collection, and analysis of ELLs' learning.

\subsection{Population Description and Sampling}

The targeted population in this study consisted mostly of teachers from kindergarten to eighth grade from different public and non-public urban, suburban, and rural schools within the KISD's boundaries. Teachers ranged from English language arts teachers to art and music instructors, most with a diverse student body in their classrooms.

Snowball sampling was chosen by the researchers. Since the researchers were not affiliated to any specific school and did not know the district's teachers, it was deemed appropriate to contact a knowledgeable person from KISD. A coordinator from the KISD's Diversity Educational Center agreed to assist with the study. The KISD diversity coordinator introduced the study and the study instrument to teachers she knew who met the characteristics of the desired population. Consequently, the survey was distributed to different teachers and school principals within KISD using the educational center's e-mail list. These educators and school administrators, in turn, distributed the survey instrument to their school personnel and acquaintances.

A total of 116 responses to the study's web-based questionnaire were collected. Of the 116,89 responses (77\%) were collected from the state of Michigan, 23 (20\%) from four other states, and four (3\%) from three different countries. As mentioned previously, the researchers' initial intention was to restrict the study to KISD teachers. However, due to the snowball sampling procedure, the survey reached national and international settings. After considering the number of respondents from various settings, the researchers ultimately decided to focus on Michigan (Table 1). They believed there would be more similarities among Michigan's schools than with other national or international schooling contexts. While student demographics may vary greatly from county to county, all public schools in Michigan have the same state standards and are administered by the same 
department of education. Table 1 provides the breakdown by county, from the largest to the smallest number of participants.

Table 1. Breakdown of questionnaire participants by county

\begin{tabular}{ll}
\hline County & Number of Participants \\
\hline Allegan County & $\mathrm{N}=4$ \\
Barry County & $\mathrm{N}=2$ \\
Berrien County & $\mathrm{N}=3$ \\
Branch County & $\mathrm{N}=3$ \\
Delta County & $\mathrm{N}=3$ \\
Grand Traverse County & $\mathrm{N}=1$ \\
Ingham County & $\mathrm{N}=1$ \\
Kent County & $\mathrm{N}=42$ \\
Lenawee County & $\mathrm{N}=2$ \\
Mecosta County & $\mathrm{N}=1$ \\
Muskegon County & $\mathrm{N}=1$ \\
Oakland County & $\mathrm{N}=1$ \\
Schoolcraft County & $\mathrm{N}=1$ \\
St. Joseph County & $\mathrm{N}=6$ \\
Van Buren County & $\mathrm{N}=1$ \\
Wayne County & $\mathrm{N}=17$ \\
\hline
\end{tabular}

Total: $\mathrm{N}=89$

\subsection{Participants' Backgrounds}

The data for this study were drawn from a population of K-8 teachers in the state of Michigan. Of the total sample $(\mathrm{N}=89), 76(85 \%)$ were female and $13(15 \%)$ were male. Two of the participants reported that they were administrators. Participants were asked to indicate their race/ethnicity: $84(94 \%)$ indicated that they were White/Anglo, four (5\%) indicated that they were Black/African American, and one (1\%) indicated that she was American Indian/Alaskan Native. The sample included 42 teachers (47\%) working in an urban district, 28 (32\%) in a rural district, and $19(21 \%)$ in a suburban district. Of the 89 participants, 53 teachers $(59 \%)$ were working in elementary schools, 21 (24\%) in middle schools, and $15(17 \%)$ in high schools. Participants in this study were also asked to indicate languages spoken. Of the total number of respondents, 12 (13\%) reported speaking Spanish and four (5\%) indicated that they spoke another language (French, Russian, Vietnamese, and Ukrainian).

The analysis of the results was reported in the form of a Pearson chi-square test. The goal of this form of analysis is to ascertain whether observations on two or more variables, expressed in a cross-tabulation table, are independent of each other. For this study, the Pearson chi-square test was used to compare obtained frequencies on specific variables with expected frequencies, providing an indication of probability that significant differences were actually found ( $p$ value). The $p$ value was set at .05 , which is the standard significance level, to ascertain whether two or more variables were independent.

\subsection{Survey Instrument}

The instrument for this study was a web-based survey (Appendix A). It consisted of a three-part questionnaire, which included demographic information and closed-form and open-ended questions. The survey questions focused on the teachers' perceptions of their preparation for teaching in heterogeneous settings, as well as their knowledge, beliefs, and school support of multiculturalism. A Likert scale was used for the closed-form questions, with possible responses ranging from "Not at all" to "A lot." No numerical scoring values were 
attached to the Likert items. The open-ended questions were designed to elicit the teachers' personal perceptions related to their role and experiences in schools as general education teachers with multicultural students.

Consultants at Grand Valley State University's Statistical Consulting Center assisted with the development of the survey by formulating appropriate Likert-type questions. They also analyzed and revised the survey instrument, made recommendations for its layout online, and provided the researchers with the link for distribution to the participants.

After an initial set of questions was developed, the draft survey instrument was field tested twice in pilot studies with eight K-8 teachers not included in the final study. After these field tests, survey items were reworded and adjusted based on the results of the field tests and the comments and suggestions of the participating teachers.

Using Cronbach's alpha internal consistency scale, the results of the two field tests showed a questionable inter-rater reliability on a number of questions. The average measure of internal consistency was between .60 and .70, which was somewhat moderate. However, the survey was deemed suitable for collecting data.

After the final survey questionnaire was developed, revised, and posted online, the consent form for the study was added. Thus, the final full survey instrument included a consent form letter and the three-part web-based questionnaire:

Part 1 related to the participants' demographic data, including gender, racial and ethnic background, years of teaching experience, grade level, and languages spoken.

Part 2 consisted of eight closed-form questions designed to identify information pertaining to training in multiculturalism, experience in teaching diverse students, desire for additional training to work effectively with diverse students, and strategies employed with diverse learners in multicultural classrooms.

Part 3 offered two open-ended questions about the participants' opinions of multicultural education and the needs of diverse students in their schools.

\subsection{Data Collection Procedures}

After the online survey link was provided for distribution, the researchers contacted the KISD diversity coordinator, who circulated the link among the participants from her organization's e-mail list. In addition, the coordinator endorsed the study by asking each contacted person to forward the link to teachers who might be willing to participate in the study.

Although the targeted population was intended to be recruited from within KISD's boundaries, the distribution of the population went beyond KISD. It ended up including populations from other counties across Michigan (e.g., Wayne County, Ingham County) and beyond. Due to variability in educational standards from state to state, the researchers elected to focus only on the information collected from counties in the state of Michigan.

\section{Analyses of Data}

Personnel at the university's Statistical Consulting Center also assisted in the data analyses following collection. Descriptive statistics and inferential statistics were used for the data analyses.

\subsection{Descriptive Statistics}

Descriptive statistics analyses allowed the researchers to describe, explain, and summarize the information gathered. The study data were summarized using a combination of tabulated description, graphical description, and statistical commentary. In addition, descriptive analyses involved examining the characteristics of individual variables by constructing a frequency distribution and percentages, which helped indicate the appropriate internal consistency of the survey items. Identifying the internal consistency of each item dealing with teachers' preparation and knowledge to instruct diverse learners revealed the extent to which the questionnaire items focused on the notion of preparation and knowledge of students' learning needs. Descriptive statistics also helped identify the distribution or spread of the marks in teachers' responses.

\subsection{Inferential Statistics}

Since the use of descriptive statistics was simply to describe the output data and did not allow the researchers to make definitive conclusions related to the study's hypothesis, inferential statistics was used to make inferences about the population from observations and data analyses. By examining relationships between variables, inferential statistics helped the researchers make judgments about the probability that an observed difference between variables was dependable or that the observed results could have occurred by chance. Moreover, since this study involved examining the characteristics of individual variables using frequency distributions, chi-square tests of independence were the specific statistics used to explore relationships between variables in the data. 
Tests of independence allowed the researchers to estimate the likelihood that a relationship between variables in a sample actually occurred in the population.

\subsection{Narrative Analysis}

Finally, a narrative analysis of open-ended questions was conducted. Responses were synthesized and analyzed to describe variations and to explain relationships between responses that emerged from the qualitative data. The narrative analysis provided information about intangible factors, such as school support, that were not apparent in the quantitative data of the study. A narrative analysis also provided a human portrait of the phenomena under study: how teachers' teaching experiences were related to each other when working with linguistically and culturally diverse students. The researchers analyzed the whole set of responses looking for common themes, categories, and relationships that emerged across the data. Responses were organized and summarized looking for similarities and differences in the data to illustrate key themes in each question.

\section{Results}

The first research questions related to teacher perceptions to deliver effectively instruction to linguistically and culturally different learners. The intent of this question was to ascertain teachers' opinions about how they felt they were prepared to teach in a diverse cultural setting. This question was approached through the survey questions that dealt with participation in diversity awareness training, the effect of that training on their professional practice, and aspects they considered critically important for their professional context.

The results revealed that having a diverse classroom and being prepared to teach students from diverse backgrounds were closely related; the two variables were dependent $(p=.002)$. Because the finding was statistically significant, the null hypothesis was rejected. As shown in Table 2, teachers (86\%) were most likely to respond that they felt well prepared or very well prepared to teach linguistically and culturally different students when those teachers were already in a diverse or somewhat diverse classroom environment. A significant minority $(45 \%)$ indicated that they felt well prepared or very well prepared even if they were not teaching in a diverse classroom environment. The researchers had hypothesized that teachers would feel unprepared to teach diverse learners. However, according to these findings, a total of $71(80 \%)$ of the participating teachers stated that they felt prepared to teach diverse learners.

Table 2. Teacher preparation to teach in linguistically and culturally diverse classrooms

\begin{tabular}{llll}
\hline & \multicolumn{3}{l}{ How prepared are you to teach linguistically and culturally diverse students? } \\
\cline { 2 - 4 } & $\begin{array}{l}\text { Not prepared/somewhat } \\
\text { prepared }\end{array}$ & $\begin{array}{l}\text { Well-prepared/very } \\
\text { well-prepared }\end{array}$ & Total* \\
\hline Not diverse & $6(55 \%)$ & $5(45 \%)$ & $11(100 \%)$ \\
Diverse/Somewhat diverse & $11(14 \%)$ & $66(86 \%)$ & $77(100 \%)$ \\
\hline
\end{tabular}

Note: Figures in parenthesis refer to percentages and have been rounded up to whole numbers.

*Total number of responses does not equal $\mathrm{N}$ of 89 ; one participant did not reply to this question.

Another subset of the first research question dealt with teacher participation in cultural awareness training. That subset related to areas such as healing racism, inclusion in the workplace, equity and social justice, and ESL and bilingual education. The chi-square test of independence revealed no significance among variables. Having a diverse classroom environment did not correlate with having participated in any of the above-mentioned areas. In this case, the researchers kept the null hypothesis as the two variables were independent from each other.

The same values were observed when participants were asked how much learning about diversity had helped them in their professional setting. The overall results were not significant, and some of the values were not large enough to be statistically significant. Teachers' learning about diversity to help them in their professional setting did not depend on how diverse or homogeneous their classroom environment was.

As for diversity training opportunities teachers would consider important if offered by the school district, the chi-squared test of independence showed significance only in language issues $(p=.023)$. As shown in Table 3, most teachers $(89 \%)$ in diverse or somewhat diverse classrooms indicated that it would be important or critically important to be trained in language issues if this course were offered by the school. Sixty-four percent of those in currently non-diverse classrooms agreed with this importance. Thus, the two variables were related. 
Table 3. Teaching diverse learners and participation in cultural awareness training

\begin{tabular}{llll}
\hline & \multicolumn{2}{l}{$\begin{array}{l}\text { If your school district wanted to offer you courses on diversity training, how } \\
\text { important would you consider language issues to be? }\end{array}$} \\
\hline & Not important/a little important & Important/critically important & Total* \\
\hline $\begin{array}{l}\text { Not diverse } \\
\begin{array}{l}\text { Diverse/Somewhat } \\
\text { diverse }\end{array}\end{array}$ & $4(36 \%)$ & $7(64 \%)$ & $11(100 \%)$ \\
\hline
\end{tabular}

Note: Figures in parenthesis refer to percentages and have been rounded up to whole numbers.

*Total number of responses does not equal $\mathrm{N}$ of 89 ; four participants did not reply to this question.

The qualitative information showed that teachers were not prepared to face and deliver instruction to a linguistically diverse set of students. They felt oftentimes inadequate and helpless when they could not assist their diverse students when they experienced difficulties understanding content related concepts. This feeling of ineffectiveness is well expressed by one of the participants who stated:

I would stand there watching my ELL students struggling with reading and telling me what the text was saying. Even when I put them in groups, they still experienced difficulties. On many occasions, I have observed that they could not communicate with group members, even after I explained what each of them was to do. I just hoped that I could be more useful to these learners. It is just overwhelming and at the end of the day, you are left with a bitter taste of being useless.

This feeling of inadequacy has brought a number of teachers to express their frustration toward the legal mandates that require that English learners be put as much as possible in the mainstream classroom. As mainstream teachers felt unprepared, they believed that English learners should be taught by teachers who have received specialized training. This sentiment was expressed by one the teachers who declared that: "Meeting the learning needs of ELLs is a big job. Students would greatly benefit from teachers who are trained to work with ELLs or are more experienced with ELL learners." The fact that mainstream teachers were unpleased with the placement options mandated by state and federal laws stemmed from the knowledge and understanding they had of their culturally and linguistically diverse learners, which constituted the second research question.

The second research sought to investigate the extent to which teachers had knowledge of and understood their linguistically and culturally different learners. As with Research Question 1, a Pearson chi-square test of independence was used to determine the relationship between having linguistically and culturally diverse classrooms and teachers' knowledge and understanding of their students' learning needs. Using the standard significance level of .05 , assumptions of independence helped to determine whether the sample results were significant enough to conclude there was a relationship between the two variables. To identify the correlation between the two variables, the researchers' survey focused on topics that included teachers experiencing cultural barriers in attempting to work with diverse learners, the incorporation of culturally related topics in daily instructional practices, and school-wide activities that promote cultural awareness among staffs and students.

Cultural barriers were further divided into different aspects: language, traditions, attitudes and beliefs, education, and poverty. Results (Table 4) indicated that language was the most challenging cultural barrier that teachers experienced. Most teachers (70\%) who had a linguistically and culturally diverse classroom experienced language-related barriers in attempting to accommodate diverse learners; only $30 \%$ indicated they did not. The difference in the results for those in non-diverse classrooms was less broad. The results proved to be statistically significant $(p=.045)$, and there was a relationship between the two variables. Thus, the results revealed that teachers were most likely to experience barriers in language when working with linguistically and culturally diverse learners in the classroom. 
Table 4. Teacher experience of cultural and linguistic barriers

\begin{tabular}{llll}
\hline & \multicolumn{3}{l}{$\begin{array}{l}\text { To what degree have you experienced language as a cultural barrier } \\
\text { when working with diverse students? }\end{array}$} \\
\hline & Not at all/A little & Moderately/A lot & Total* \\
\hline $\begin{array}{l}\text { Not diverse } \\
\begin{array}{l}\text { Diverse/Somewhat } \\
\text { diverse }\end{array}\end{array}$ & $6(60 \%)$ & $5(40 \%)$ & $11(100 \%)$ \\
\hline
\end{tabular}

Note: Figures in parenthesis refer to percentages and have been rounded up to whole numbers.

* Total number of responses does not equal $\mathrm{N}$ of 89; four participants did not reply to this question.

When participants were asked about the extent to which they incorporated cultural topics into everyday lessons, and the degree to which activities were emphasized in schools that promoted cultural awareness within the school, the chi-square tests of independence showed no statistical significance. The researchers kept the null hypothesis; that is, the inclusion of cultural topics into daily teaching practice and school-wide promotion of cultural awareness were not likely to be related to classroom or school cultural and linguistic diversity.

The qualitative data showed that the teachers knew that it was essential to seek to understand the various cultures present in their classrooms. This was expressed by one of the teachers that asserted that: "You cannot fully understand a learner until you are aware where they came from, what he believes, and his cultural upbringing." Similar teachers seemed to be aware of the specific needs and challenges that the English learners posed. However, tailoring instruction to include their various learners was a demanding task. They stated that the pre-service as well in service training they received did not prove to be helpful in integrating their students' cultures in lesson plans and instructional delivery. One participant expressed how the training they received did not help them to be effective with English learners: "In college as well as during the professional development workshops that our districts organizes, instructors focus on culture and racial healing, but not how to integrate students' backgrounds in our teaching" This quotes underscores the fact that teachers are aware of the challenges that ELs pose that do not have the abilities and skills to meet their needs.

\section{Analysis of the Findings}

Two elements emerged that the researchers believed to be most important in teachers' perceptions of their preparation and their understanding of professional interaction with linguistically and culturally diverse students. These elements were language needs and diversity awareness.

\subsection{Language Needs}

The results from this study showed that teachers felt they had neither the linguistic background nor the methodology to teach ELLs in the mainstream classroom. Teachers stated that linguistically and culturally diverse students require extensive support to learn and develop academic English. They expressed their lack of training in language issues, how important training in language issues was to them, and how this lack of training affected their ability to help ELLs. As one of the participants in this study stated, "Meeting the learning needs of ELLs is a big job. Students would greatly benefit from teachers who are trained to work with ELLs or are more experienced with ELL learners." Many participants expressed the need to be provided with the knowledge and skills that would allow them to teach content-area subjects effectively to ELLs.

Meeting ELLs' learning needs is a critical concern for educators because these learners are expected to master content in English. This poses a great challenge for teachers to meet ELLs' language and academic needs. The National Education Association (2008) has already reported that teachers have expressed frustration about receiving little to no professional development or in-service training about methodologies to teach ELLs. Echevarria et al. (2007) and Rothenberg and Fisher (2007) also argued that research has shown many teachers are unprepared to teach in the diverse classroom. Language teaching methodological issues and diversity are intertwined.

\subsection{Diversity Awareness}

The second critical issue that teachers felt they were unprepared to deal with related to integrating cultural elements into their daily instructional content. Although most teachers reported that they had received cultural awareness training, they were still unable to incorporate that cultural knowledge into every lesson. As stated by one of the participants: 
Teachers strived to meet the needs of each student by taking into account their specific academic and cultural development needs. However, tailoring lessons to include cultures different from the Anglo-Saxon's showed it to be an arduous task as it required opening the door to a wide range of topics.

The findings in this study revealed that school districts in Michigan strive to provide educational practitioners with professional development workshops that focus on diversity awareness. However, educators still are not fully prepared to work in heterogeneous classrooms. Most workshops are geared toward discussing specific cultural and racial topics (e.g., healing racism) rather than designing cultural curricula and developing pedagogical methods for implementing these curricula. Professional development workshops do not appear to prepare teachers to be effective in integrating cultural elements into their daily lessons and interactions with ELLs.

\section{Discussion}

Teachers are critically important in helping students meet their academic needs and in preparing them for the workforce (Arias et al., 2010). Sleeter (2001) has argued that multicultural and culturally responsive teachers need to be brought into schools to meet the needs of diverse students. The way teachers are prepared today to meet the needs of these diverse learners varies across states. This preparation is based on state and federal policies and mandates (Arias, Faltis, \& Ramirez-Marin, 2010).

There were two purposes for this study: (a) to investigate teachers' perceptions of their preparation, in Michigan, to teach linguistically and culturally diverse students, and (b) to explore the kind of knowledge and understanding that teachers felt they had of their diverse students' learning needs.

Findings from this study revealed that teachers' perceptions of their readiness to teach linguistically and culturally diverse students correlated with whether the classroom was culturally diverse or homogenous. Similarly, the participating teachers' knowledge about these diverse learners' academic needs was related to the diversity within the classroom environment. The more diverse linguistically and culturally their classroom was, the more teachers felt they needed knowledge and skills related to teaching these linguistically and culturally diverse learners.

Findings revealed that teachers recognized explicit knowledge about cultural diversity is essential to meeting the educational needs of an ethnically and linguistically diverse student body. Teachers, to some extent, felt prepared to teach in culturally diverse classroom environments. However, they did not feel prepared to deliver instruction to linguistically different students. Results also revealed that teachers need effective training in methodology for teaching disciplinary content and language to ELLs. Teachers agreed that professional development courses, beyond initial training in teacher training colleges, should focus on ELLs' issues.

In addition, findings from this study showed that teachers have explored ways in which their educational practices might enhance understanding and appreciation of linguistic and cultural diversity. However, what teachers found challenging was the integration of different aspects of diversity (e.g., language, cultural background) into everyday lessons in different subjects. Teachers were unable to incorporate their knowledge into every lesson; using students' diversity as an asset in every lesson proved to be a challenge. The results also indicated that teachers considered the culture and beliefs of all students to be very important. However, customizing lessons to include cultures and beliefs was an arduous task.

The results from this study show that teachers are gradually becoming culturally responsive. The participating teachers actively sought knowledge about other cultures and ethnic groups through means available to them. In addition, they implemented accommodations for linguistically and culturally different students (e.g., using culturally specific learning style strategies, paying attention to cultural values and behaviors). They also reported that they examined beliefs, values, and behaviors within the school environment that could have positive or negative effects on culturally and linguistically diverse learners. Nonetheless, many educators found the task of meeting students' diverse needs to be overwhelming.

The fact that teachers found they were unprepared to teach linguistically different students can be related to the U.S. national educational environment. Many states in the U.S. do not require their educational practitioners to be trained in English language development or bilingual education teaching methodologies. Michigan is such a state. However, as school districts have had to be responsive to federal mandates of the No Child Left Behind Act (U.S. Department of Education, 2008), some teachers have received training that prepares them to teach in a heterogeneous setting.

Although in-service professional workshops are organized by various school districts to develop teachers' cultural sensitivity, they do not specifically deal with integrating students' cultures into daily instructional 
practices. Hence, teachers are unable to effectively integrate students' cultural backgrounds into their planning and lesson delivery. These workshops often aim at only raising awareness or developing sensitivity toward various cultures and races.

\subsection{Implications and Recommendations}

The results from this study have important implications for classroom teachers and school and district administrators. Today's classrooms are linguistically and culturally diverse. As such, all teachers need to incorporate strategies that support not only the learning of linguistically and culturally diverse learners, but also the learning of native English speakers (Echevarria et al., 2007). Teachers must be prepared to work with diverse student populations and to incorporate practices that are consistent with the principles of multicultural education (Nieto, 2002). Practices such as the creation of a classroom community that models culturally responsive teaching and promotes understanding about students' learning styles (Nieto, 2002) must be implemented and should become part of the daily instructional routines. Teachers can use what they know about their students to make learning meaningful. One way of implementing cultural knowledge in daily practices is the use of funds of knowledge. However, before that, curricula need to be revised to include the exploration of cultural issues such as language and cultural backgrounds.

Another implication that can be drawn from these results relates to language and academic content-area teaching. Mainstream teachers and disciplinary area teachers-regardless of whether school districts provide workshops focused on methodologies for teaching English to speakers of other languages-must adapt their professional practices to the academic and linguistic level of their students. Echevarria et al. (2007) and Rothenberg and Fisher (2007) have provided specific strategies that range from purely teaching strategies of content to integrating students' cultural capital into instruction.

Administrators at building and district main offices need to provide teachers with hands-on in-service workshops during which teachers design and implement lesson plans that integrate culture, language, and content. Cultural sensitivity or awareness workshops are insufficient in helping teachers be effective in the heterogeneous classroom. Given that most classroom practitioners lack experience in teaching linguistically and culturally diverse learners, courses specific to language and culture teaching strategies should be given in schools. The knowledge and skills gained from these courses can lead to pedagogical practices that will incorporate diversity into different lesson topics, regardless of the discipline and content.

\subsection{Study Limitations}

Although this study used a mixed method design as an investigation tool, the sampling method used could limit the generalizability of the findings. Snowballing is a non-probabilistic sampling method that relies heavily on referrals from initial participants to generate additional participants. As such, the researchers did not have control over the number of participants. That was clearly shown through the participation of teachers outside of Kent County and even the state of Michigan. In addition, other teachers beyond the participants' professional networks could not participate in the study.

Another limitation was the instrument used, which consisted of a Likert-scale questionnaire with two open-ended questions. Future studies could employ interviews and classroom observations to study the extent to which teachers integrate culture into their daily lessons.

\section{Conclusion}

This study showed that, although many mainstream teachers $(80 \%)$ stated they felt prepared to teach in a classroom that was culturally and linguistically heterogeneous, in some ways they had neither the cultural knowledge nor the professional skills to implement curricula that were congruent with students' cultures and linguistic backgrounds. It is imperative that teacher training colleges implement courses that prepare teachers to develop curricula and materials that are compatible with students' home cultures. Likewise, schools districts need to implement professional development workshops that go beyond cultural sensitivity issues to show their teachers how to plan and teach leaning units that integrate cultures across the curriculum. States that do not have policies compelling schools to integrate learners' cultural and linguistic backgrounds need to pass such laws. Otherwise, school districts will not feel obligated to adapt their practices to culturally and linguistically different students' issues. Academic success and high test scores will not be achieved if very limited, and often inappropriate, accommodations are applied in the learning setting.

\section{References}

Arias, M. B., Faltis, C. C., \& Ramirez-Marin, F. (2010). Identifying relevant competencies for secondary teachers of English learners. Bilingual Research Journal, 33(3), 307-328. 
Arias, M. B., Garcia, E., Harris-Murria, N. J., \& Serna, C. (2010). Developing responsive teachers: A challenge for a demographic reality. Journal of Teacher Education, 61(1-2), 132-142. http://dx.doi.org/10.1177/0022487109347878

Banks, J. A. (2005). Cultural diversity and education (5th ed.). Boston, MA: Pearson.

Banks, J. A., \& Banks, C. A. M. (1997). Multicultural education: Issues and perspectives (3rd ed.). Boston, MA: Allyn and Bacon.

Bernhard, J. K., Diaz, C. F., \& Allgood, I. (2005). Research-based teacher education for multicultural contexts. Intercultural Education, 16(3), 263-277. http://dx.doi.org/10.1080/14675980500211873

Brown, D. (2003). Urban teachers' use of culturally responsive management strategies. Theory into Practice, 42(4), 277-282.

Darling-Hammond, L. (2006). Constructing 21st century teacher education. Journal of Teacher Education, 57(3), 300-314.

Donato, R., Henze, R., \& Lucas, T. (1990). Promoting the success of Latino language-minority students: An exploratory study of six high schools. Harvard Educational Review, 60(3), 315-340.

Echevarria, J., Vogt, M. E., \& Short, D. J. (2007). Making content comprehensible for English learners. The SIOP model. Boston, MA: Pearson.

Gay, G. (2000). Culturally responsive teaching: Theory, research, and practice. New York, NY: Teachers College Press.

Gay, G. (2002). Preparing culturally responsive teachers: Rethinking the curriculum. Journal of Teacher Education, 53(1), 20-32.

Gay, G. (2010). Acting on beliefs in teacher education for cultural diversity. Journal of Teacher Education, 61(1-2), 143-152.

Gonzalez, N., \& Moll, L. C. (2002). Cruzando el puente: Building bridges to funds of knowledge. Educational Policy, 16(4), 623-641.

Guillet, E., Martinek, T. J., Sarrazin, P. G., \& Trouilloud, D. D. O. (2002). The influence of teacher expectations on student achievement in physical education classes: Pygmalion revisited. European Journal of Social Psychology, 32(5), 591-607.

Guo, Y., Arthur, N., \& Lund, D. (2009). Intercultural inquiry with pre-service teachers. Intercultural Education, 20(6), 565-577. http://dx.doi.org/1080/14675980903448619

Guskey, T. T. R. (2002). Professional development and teacher change. Teachers and Teaching, Theory and Practice, 8(3), 381-391.

Gutiérrez, R. (2000). Advancing African-American, urban youth in mathematics: Unpacking the success of one math department. American Journal of Education, 109(1), 63-111.

Gutstein, E., Lipman, P., Hernandez, P., \& Reyes, R. (1997). Culturally relevant mathematics teaching in a Mexican American context. Journal for Research in Mathematics Education, 28(6), 709-737.

Hutchinson, M., \& Hadjioannou, X. (2011). Better serving the needs of limited English proficient (LEP) students in the mainstream classroom: Examining the impact of an inquiry-based hybrid professional development program. Teachers \& Teaching, 17(1), 91-113. http://dx.doi.org/10.1080/13540602.2011.538499

Johnson, L. (2003). Multicultural policy as social activism: Redefining who "counts" in multicultural education. Race, Ethnicity and Education, 6(2), 107-121. http://dx.doi.org/10.1080/1361332032000076436

Karatzia-Stavlioti, E., Roussakis, Y., \& Spinthourakis, J. A. (2009). Pre-service teacher intercultural sensitivity assessment as a basis for addressing multiculturalism. Intercultural Education, 20(3), 267-276.

Kent Intermediate School District. (2011). Collaborating to serve students, schools and communities: Annual report 9-10. Retrieved from http://www.kentisd.org/downloads/administrative_files/annual_report_0910.pdf

Lucas, T., Villegas, A. M., \& Freedson-Gonzalez, M. (2008). Linguistically responsive teacher education: Preparing classroom teachers to teach English language learners. Journal of Teacher Education, 59(4), 361-373. 
National Clearinghouse for English Language Acquisition. (2008). Educating English language learners: Building teacher capacity. Retrieved from http://www.ncela.gwu.edu/files/uploads/3/Educating ELLsBuildingTeacherCapacityVol1.pdf

National Clearinghouse for English Language Acquisition. (2011). The growing numbers of English learner students, 1998/99-2008/09. Retrieved from http://www.ncela.gwu.edu/files/uploads/9/growingLEP_0809.pdf

National Education Association. (2008). English language learners face unique challenges (Policy Brief PB05). Retrieved from https://www.nea.org/assets/docs/HE/ELL_Policy_Brief_Fall_08_\%282\%29.pdf

Nieto, S. (2000). Placing equity front and center: Some thoughts on transforming teacher education for a new century. Journal of Teacher Education, 51(3), 180-188.

Nieto, S. (2002). Language, culture, and teaching: Critical perspectives for a new century. Mahwah, NJ: L. Erlbaum.

Rothenberg, C., \& Fisher, D. (2007). Teaching English language learners: A differentiated approach. Upper Saddle, NJ: Pearson.

Santoro, N. (2007). "Outsiders" and "others": 'Different' teachers teaching in culturally diverse classrooms. Teachers \& Teaching, 13(1), 81-97. http://dx.doi.org/10.1080/13540600601106104

Siwatu, K. (2007). Preservice teachers' culturally responsive teaching self-efficacy and outcome expectancy beliefs. Teaching and Teacher Education, 23(7), 1086-1101.

Sleeter, C. (2001). Preparing teachers for culturally diverse schools: Research and the overwhelming presence of whiteness. Journal of Teacher Education, 52(2), 94-106.

Sleeter, C. (2008). An invitation to support diverse students through teacher education. Journal of Teacher Education, 59(3), 212-219.

U.S. Department of Education. (2008). No Child Left Behind Act of 2001, 20 U.S.C. § 6319. Retrieved from http://www2.ed.gov/nclb/overview/intro/reauth/index.html

Verdugo, R. R., \& Flores, B. (2007). English-language learners: Key issues. Education and Urban Society, 39(2), 167-193.

Villegas, A. M., \& Lucas, T. (2002). Preparing culturally responsive teachers. Journal of Teacher Education, 53(1), 20-32.

Woods, P. R., Jordan, P. J., Loudoun, R., Troth, A. C., \& Kerr, D. (2006). Effective teaching in the multicultural business classroom. Journal of Teaching in International Business, 17(4), 27-48. http://dx.doi.org/10.1300/j066v17n04_03

\section{Copyrights}

Copyright for this article is retained by the author(s), with first publication rights granted to the journal.

This is an open-access article distributed under the terms and conditions of the Creative Commons Attribution license (http://creativecommons.org/licenses/by/3.0/). 